\title{
Implementasi Ethereum Blockchain dan Smart Contract pada Jaringan Smart Energy Meter
}

\author{
Anggun Mugi Mabruroh ${ }^{1}$, Favian Dewanta ${ }^{2}$, Aulia Arif Wardana ${ }^{3}$ \\ ${ }^{1,2}$ Teknik Telekomunikasi, Fakultas Teknik Elektro, Universitas Telkom \\ ${ }^{3}$ Informatika, Fakultas Informatika, Universitas Telkom \\ Telkom University, Jl. Telekomunikasi No. 1, Terusan Buahbatu - Bojongsoang, Sukapura, Dayeuhkolot, \\ Bandung, Jawa Barat
}

Diterima: 31 Agustus 2021. Disetujui: 23 September 2021. Dipublikasikan: 18 Oktober 2021.

\begin{abstract}
Conventional databases on Internet of Things (IoT) technology have a centralized storage system on a database server. If the server is damaged and fails to work, then the service will also crash and there is also the possibility of data loss. Therefore, this study proposes the creation of an IoT device, namely a smart energy meter, by implementing a blockchain system as a distributed database. This blockchain system implements a private blockchain network that is realized using the Ethereum framework. The sensor data will be read by the Raspberry Pi $4 B$ and sent to node 1 via MQTT. Node 1 will save the data to the block. Two Ethereum account nodes will validate the block. If accepted then the block will be stored on the blockchain and create a new block chain. In the storage process, each node will work according to a predefined smart contract created using solidity and accessed using the web3 API. Successfully saved data will be displayed to the user's web. Based on the results of testing the system delay from sensors to the website, the use of blockchain compared to conventional databases has an effect on increasing the overall delay, which is 8.5274 seconds, which is the average calculation of the submit transaction delay for transaction processing and transaction receipt for the data verification process. However, these results do not reduce the quality of the smart energy meter system because this system does not require a fast response in reporting the results of electric power usage. In addition, the number of nodes and block size do not affect the performance of the proof of authority consensus algorithm used in this blockchain system.
\end{abstract}

Keywords: Internet of Things, blockchain, smart contract, Ethereum, MQTT

Abstrak-Database konvensional pada teknologi Internet of Things (IoT) memiliki sistem penyimpanan secara terpusat pada database server. Jika server tersebut rusak dan gagal bekerja, maka layanan pun akan ikut lumpuh dan ada kemungkinan juga kehilangan data. Oleh karena itu, penelitian ini mengusulkan pembuatan perangkat IoT, yakni smart energy meter, dengan menerapkan sistem blockchain sebagai database terdistribusi. Sistem blockchain ini menerapkan jaringan privat blockchain yang direalisasikan dengan menggunakan framework Ethereum. Data sensor akan dibaca oleh Raspberry Pi 4B dan dikirimkan ke node 1 melalui MQTT. Node 1 akan menyimpan data ke blok. Dua node akun Ethereum akan memvalidasi blok tersebut. Jika diterima maka blok akan disimpan pada blockchain dan membuat rantai blok baru. Dalam proses penyimpanan, setiap node akan bekerja berdasarkan dengan smart contract yang telah didefinisikan sebelumnya yang dibuat dengan menggunakan solidity dan diakses menggunakan web3 API. Data yang berhasil disimpan akan ditampilkan ke web pengguna. Berdasarkan hasil pengujian delay sistem dari sensor hingga ke website, penggunaan blockchain jika dibandingkan database konvensional berpengaruh terhadap penambahan delay secara keseluruhan, yakni 8,5274 detik yang merupakan kalkulasi rata-rata delay submit transaction untuk proses transaksi dan transaction receipt untuk proses verifikasi data. Namun, hasil ini tidak mengurangi kualitas sistem smart energy meter karena sistem ini tdak memerlukan respon yang cepat dalam melaporkan hasil penggunaan daya listrik. Selain itu, jumlah node dan ukuran blok tidak mempengaruhi kinerja algoritma konsensus proof of authority yang digunakan dalam sistem blockchain ini.

Kata kunci: Internet of Things, blockchain, smart contract, Ethereum, MQTT

\section{PENDAHULUAN}

Internet of Things (IoT) memberikan jaminan keamanan, kenyamanan, kemudahan dan peningkatan kualitas hidup pengguna, IoT menghubungkan antar perangkat yang dapat terhubung dengan internet[1]. IoT memungkinkan sensor dan actuator yang terhubung ke komputer untuk memfasilitasi produk dan layanan baru dengan mengurangi biaya, meningkatkan efisiensi, dan meningkatkan kegunaan sistem yang ada[2]. Implementasi IoT ada dipelbagai bidang dan tempat seperti smart home, smart city, smart corporate dan lain sebagainya. Smart home adalah salah satu dari penerapan IoT segala benda yang ada di rumah dapat saling berkomunikasi dan berinteraksi melalui internet. Sistem otomasi rumah saat ini sangat 
populer bahkan sampai dikaitkan dengan tenaga listrik serta kebutuhan listrik juga sangat tinggi hampir semua peralatan rumah tangga menggunakan listrik[3].

Pengelolaan jaringan secara terpusat membutuhkan infrastruktur komunikasi dan informasi mahal. Selain itu, banyaknya ancaman serangan siber di internet menyebabkan pengelolaan database terpusat menjadi kurang aman. Sebagai solusinya, teknologi blockchain saat ini banyak diusulkan sebagai salah satu solusi untuk menambah keamanan, yakni dengan mendistribusikan database ke semua ledger dan juga dengan tambahan hash yang saling terhubung dengan blok data sebelumnya, sebagaimana dibahas di penelitian[4][5].

Teknologi pengukuran data listrik yang sudah ada masih menggunakan sistem terpusat di mana keamanan data listrik masih kurang aman yaitu disimpan pada suatu database pusat. Berdasarkan pada penelitian sebelumnya pembuatan sistem smart energy meter dengan menggunakan algoritma AES untuk pertukaran data pada jaringan IoT[6]. Data blockchain smart energy meter dibangun di cloud storage, setiap cloud storage memiliki salinan data lalu ketika blok data disimpan, setiap cloud storage provider harus verifikasi blok data tersebut[7]. Pada penelitian tersebut, jika administrator pusat suatu saat tidak bertanggung jawab dengan memanipulasi data maka pengguna listrik tidak mengetahui jika data mereka sudah dimanipulasi. Selain itu jika suatu saat server database down maka akan kehilangan data pada database tersebut.

Pada penelitian ini, penulis melakukan perancangan, pembuatan dan penelitian mengenai perangkat IoT smart energy meter untuk pemantauan listrik yaitu sensor daya akan mendeteksi data daya pada suatu beban. Kemudian data daya tersebut akan dikirimkan dari Raspberry Pi ke node 1 menggunakan Message Queuing Telemetry Transport (MQTT) karena communication overhead yang rendah dan efisiensi sumber daya[8]. Data yang diterima kemudian diproses untuk disimpan ke database blockchain, lalu data akan ditampilkan pada web pengguna.

\section{TINJAUAN PUSTAKA}

\section{A. MQTT}

Protokol MQTT atau Message Queuing Telemetry Transport adalah protokol yang dirancang khusus untuk komunikasi "mesin ke mesin" di mana bekerja dengan overhead yang rendah (> 2 byte) sehingga konsumsi power supply cukup kecil[9].
MQTT membutuhkan node publisher, subscriber dan broker.

\section{B. Blockchain}

Blockchain adalah sistem cryptocurrency pertama yang diterapkan oleh bitcoin di mana blockchain mengatasi permasalahan keamanan data dan keselamatan data IoT yang rentan[10].

Blockchain adalah database yang terdistribusi untuk mendistribusikan struktur data dan dibagikan ke seluruh node anggota[11]. Struktur data tersebut berupa daftar record yang disebut blok, di mana di dalam setiap blok tersebut memiliki timestamp[11] dan kode hash yang terhubung dengan blockhash sebelumnya, sehingga setiap blok saling terkait satu sama lain menggunakan hash masing-masing blok tersebut.

\section{Smart Contract}

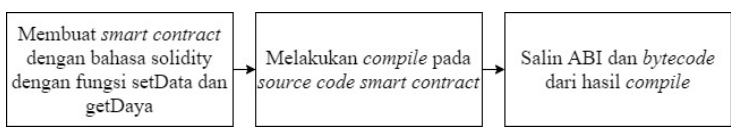

Gambar 1. Proses Compile untuk Mendapatkan Bytecode dan $\mathrm{ABI}$

Smart contract yaitu kontrak yang dibuat untuk perjanjian antara beberapa node berdasarkan jenis algoritma consensus. Kontrak tersebut dalam bentuk source code di mana penulis menggunakan bahasa solidity. Solidity adalah bahasa pemrograman mirip dengan c++ yang memiliki ekstensi .sol di mana solidity berorientasi obyek untuk merancang smart contract agar dapat berjalan di Ethereum Virtual Machine. Di dalam source code solidity dapat diprogram untuk mendapatkan data dan menyimpannya serta menampilkan data. File .sol tersebut akan dikompilasi, kemudian menghasilkan bytecode yang digunakan untuk referensi fungsi dan kontrak untuk dieksekusi di EVM. Selain bytecode, hasil compile yang kedua adalah ABI (Application Binary Interface) yang merupakan daftar fungsi dan kontrak berbentuk JSON (Javascript Object Notation)[12]. Proses compile smart contract dapat dilihat pada Gambar 1. Smart contract dapat menentukan aturan dan menghasilkan kode untuk diterapkan pada jaringan blockchain. Smart contract tidak dapat dihapus secara default, dan interaksi dengan smart contract tidak dapat dihilangkan.

\section{Ethereum}

Ethereum merupakan platform untuk menyediakan atau membuat smart contract pada teknologi blockchain[13]. Ethereum memiliki komputasi virtual yaitu Ethereum Virtual Machine (EVM) di mana setiap node yang ada di jaringan mengirimkan permintaan agar EVM ini mendapatkan wewenang melakukan komputasi. Node lain melakukan verifikasi, validasi dan 
melaksanakan komputasi. Hal ini menyebabkan perubahan status di EVM, yang akan disebarkan ke seluruh jaringan. Permintaan komputasi disebut permintaan transaksi di mana semua catatan transaksi serta status EVM disimpan di blockchain, kemudian disimpan dan disetujui oleh semua node[14]. EVM mengeksekusi kode ABI dan dapat diakses publik oleh pengguna manapun dan permissionless. Hasil dari blockchain Ethereum merupakan aplikasi terdistribusi. Pada Ethereum, pembuatan smart contract menggunakan bahasa solidity. Smart contract Ethereum memiliki contract yang kuat, publik dan transparan. Ethereum menggunakan algoritma konsensus proof of work dan proof of authority [15].

\section{E. Proof of Authority}

Algoritma Konsensus Proof of Authority memiliki jaringan yang bergantung pada sekelompok node otoritas yang merupakan validator yang telah disetujui sebelumnya. Kemudian melakukan verifikasi transaksi dan membangun blok baru. Validator harus mematuhi serangkaian aturan agar dapat dipercaya. Salah satunya mengharuskan mereka untuk terdaftar di database blockchain dengan identitas yang sama dengan yang mereka miliki. Agar jaringan berfungsi, lebih banyak aturan harus diikuti. Pada penelitian ini, penulis menggunakan konsensus proof of authority dimana authority atau ledger node bekerja sebagai validator dan melakukan verifikasi publik. Protokol ini dapat digunakan di jaringan publik atau pribadi[16]. Gambar 2 merupakan ilustrasi sederhana mengenai letak ledger account 1 pada masing-masing node.
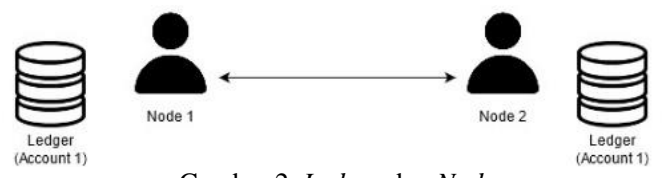

Gambar 2. Ledger dan Node

\section{F. Web3.py API}

Web3.py adalah library python untuk berinteraksi dan terhubung dengan sistem Ethereum. Web3.py memiliki beberapa API untuk menggunakan fungsi Ethereum diantaranya yaitu untuk terhubung dengan jaringan Ethereum pribadi, memanggil fungsi smart contract dan melakukan transaksi yang menghasilkan blockhash. Sebelumnya hanya terdapat web3 API berbasis javascript tapi sekarang sudah berkembang dan berevolusi untuk kebutuhan dan kenyamanan pengembang python[17].

\section{G. Geth}

Geth atau go-ethereum adalah salah satu implementasi dari protokol Ethereum yaitu bahasa pemrograman open-source yang dapat dipasang pada semua sistem operasi[18]. Pada Ethereum terdapat tiga jenis node yaitu full-node, light node dan node arsip. Full-node memiliki beberapa tugas untuk menyimpan data blockchain lengkap, berpartisipasi dalam validasi blok, memverifikasi semua blok dan status. Semua state dapat diturunkan dari full node. Full-node juga melayani jaringan dan menyediakan data berdasarkan permintaan. Selanjutnya light node yang memiliki beberapa tugas untuk menyimpan rantai header dan meminta yang lainnya. Light-node dapat memverifikasi validitas data terhadap akar status di header blok. Light-node berguna untuk perangkat berkapasitas rendah, seperti perangkat tertanam atau ponsel, yang tidak mampu menyimpan gigabyte data blockchain. Dan yang terakhir adalah node arsip yang memiliki beberapa tugas untuk menyimpan semua yang disimpan dalam simpul penuh dan membangun arsip status historis. Node arsip diperlukan jika ingin menanyakan sesuatu seperti saldo akun pada blok. Data ini mewakili unit terabyte yang membuat node arsip kurang menarik bagi pengguna rata-rata tetapi dapat berguna untuk layanan seperti penjelajah blok, vendor dompet, dan analitik rantai[19]. Kedua node yang penulis buat yaitu node 1 dan node 2 menggunakan full-node.

\section{METODE PENELITIAN}

\section{A. Metodologi}

Penelitian diawali ketika ada masalah muncul saat meninjau jurnal dan paper konferensi tentang bagaimana mengamankan data Internet of Things[2]. Beberapa sistem telah mengantisipasi masalah ini dengan menerapkan algoritma AES untuk melakukan enkripsi dan dekripsi data[6]. Namun, jika administrator database pusat memanipulasi data maka data tersebut akan berubah. Selain itu jika server database down maka akan kehilangan data pada database server. Sehingga memerlukan database yang tidak terpusat. Blockchain merupakan database yang desentralisasi dan terdistribusi. Maka dari itu, penulis melakukan penelitian yaitu menerapkan blockchain pada sistem penyimpanan data smart energy meter.

\section{B. Metode DSRM (Design Science Research Methodology)}

DSRM adalah metode dalam membangun sistem pada penelitian. DSRM cocok untuk software developer, sedangkan pada sistem yang penulis buat membangun perangkat lunak dan perangkat keras. Sehingga DSRM diterapkan pada pembuatan sistem prototipe blockchain. Fase pertama adalah identifikasi masalah, yang dibahas pada bagian pendahuluan melalui frasa awal dari metode penelitian. Tahap kedua adalah desain dan pengembangan sistem dibahas pada bagian Desain Sistem, Desain Perangkat Smart Energy Meter dan 
Desain Perangkat Lunak. Tahap demonstrasi dan evaluasi dibahas pada bagian Hasil dan Pembahasan. Komunikasi dibahas pada bagian Kesimpulan. Metode pengujian yang digunakan untuk menguji prototipe adalah pengukuran delay dan performa sistem. Pertama, pengukuran delay untuk menguji apakah semua komponen yang digunakan dalam prototipe bekerja sebagaimana mestinya, sedangkan pengukuran performa sistem untuk menentukan apakah prototipe akan menjadi solusi yang tepat dengan menguji kualitas algoritma konsensus Proof of Authority, web pengguna dan CPU node 1.

\section{Desain Sistem}

Pada Gambar 3 adalah desain sistem smart energy meter yang menerapkan blockchain dirancang untuk memberikan keamanan pada penyimpanan database dimana menggunakan blockchain. Terdapat beberapa tahap untuk data bisa ditampilkan ke web pengguna. Tahap pertama yaitu menghubungkan sensor PZEM-004T dengan Raspberry Pi 4B. Untuk proses pembacaan sensor di Raspberry $\mathrm{Pi}$ 4B menggunakan pemrograman python. Setelah data terbaca maka tahap kedua yaitu pengiriman data daya dari Raspberry Pi 4B ke node 1 di virtual machine virtualbox. Pengiriman tersebut menggunakan protokol komunikasi yaitu MQTT dimana Raspberry Pi 4B sebagai publisher atau yang mengirim data dan node 1 sebagai subscriber yaitu yang menerima data. Dalam penelitian ini penulis menggunakan library paho-mqtt yaitu library MQTT dari python. Setelah itu tahap ketiga, data yang diterima di node 1 kemudian disimpan ke database blockchain dengan memanggil fungsi setData pada smart contract menggunakan API web3py. Setelah tersimpan, data tersebut akan ditampilkan di web pengguna memanggil fungsi getDaya pada smart contract menggunakan API web3py.

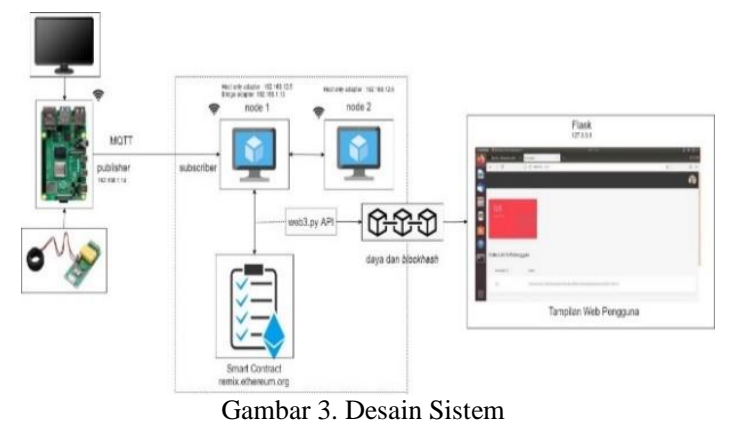

a. Diagram Alir Pembuatan Perangkat dan Sistem Blockchain

Pada Gambar 4 adalah diagram alir tahapan pengerjaan perangkat smart energy meter dan penerapan sistem blockchain meliputi beberapa tahap yaitu tahap pertama adalah menentukan latar belakang dan tujuan perancangan implementasi sistem blockchain pada jaringan smart energy meter. Tahap kedua yaitu pematangan konsep dengan mencari referensi dan informasi pembuatan sistem blockchain untuk lalu lintas data internet of things dengan tujuan agar nantinya dalam pembuatan dapat berjalan lancar dengan hasil yang diinginkan. Tahap ketiga yaitu menyiapkan kebutuhan perangkat seperti sensor PZEM-004T dan Raspberry Pi 4B untuk membuat perangkat smart energy meter. Tahap keempat dan kelima perancangan prototype adalah percobaan perangkat smart energy meter menerapkan sistem blockchain dengan menggunakan fungsifungsi yang ada pada program solidity smart contract. Tahap keenam adalah pengecekan apakah sistem blockchain dapat diterapkan pada jaringan smart energy meter atau tidak. Setelah itu ke tahap tujuh yaitu pengujian performa di mana pengujian pada data daya yang diterima node 1 dapat disimpan dengan memanggil fungsi setData dari program solidity smart contract dan diambil atau ditampilkan kembali dengan memanggil fungsi getDaya serta menghasilkan blockhash dari setiap transaksi penyimpanan data daya tersebut. Selain itu pengukuran delay pada pengiriman data daya ke node 1, pengukuran delay pada transaksi dan penampilan kembali data daya tersebut ke web pengguna. Kemudian tahap analisis dan kesimpulan yaitu menganalisis dari beberapa hasil pengukuran delay dan membuat kesimpulan dari analisis tersebut.

\section{b. Diagram Blok}

Gambar 5 adalah diagram blok proses kerja secara keseluruhan sistem smart energy meter yaitu mulai dari sensor yang terhubung dengan sumber tegangan dari beban yang dideteksi dayanya dan dapat dibaca pada monitor yang terhubung dengan Raspberry Pi 4B dengan menggunakan program dari python agar dapat mengakses sensor dan membaca datanya. Setelah itu mengirimkan data daya tersebut ke node 1 dengan menggunakan protokol komunikasi MQTT yaitu data daya tersebut disimpan pada database blockchain dan ditampilkan kembali di web pengguna. 


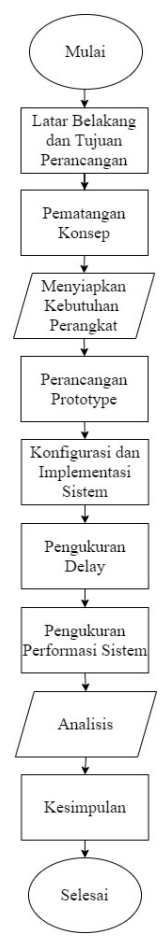

Gambar 4. Diagram Alir Pembuatan Perangkat dan Sistem Blockchain

\begin{tabular}{|c|c|c|}
\hline \multirow[t]{3}{*}{$\begin{array}{l}\text { Data masuk ke fungsi } \\
\text { setData web3 API }\end{array}$} & $\begin{array}{l}\text { Data fungsi setData } \\
\text { akan melakukan } \\
\text { transaksi dan } \\
\text { menghasilkan blok }\end{array}$ & $\rightarrow \begin{array}{c}\text { Blok data akan } \\
\text { disimpan ke blockchain }\end{array}$ \\
\hline & & $\downarrow$ \\
\hline & $\begin{array}{c}\text { Data daya dan } \\
\text { blockhash ditampilkan } \\
\text { pada web pengguna }\end{array}$ & $\begin{array}{c}\text { Memanggil fungsi } \\
\text { getDaya web3 API dan } \\
\text { memanggil bloknya }\end{array}$ \\
\hline
\end{tabular}

Gambar 5. Diagram Blok Proses Kerja Sistem Smart Energy Meter

Gambar 6 menunjukkan alur data dari sensor PZEM-004T hingga ke web pengguna yang sebelumnya melalui proses pengolahan data pada sistem blockchain. Data yang diterima oleh node 1 disimpan ke database dengan menggunakan fungsi setData yang dipanggil dengan web3.py API. Setiap data yang disimpan ke database blockchain, node 1 mengajukan transaksi dan menghasilkan blok. Data diambil dengan fungsi getDaya yang dipanggil dengan web3.py API. Data daya yang diambil tersebut ditampilkan ke web pengguna.

\begin{tabular}{|c|c|c|}
\hline \multirow[t]{3}{*}{\begin{tabular}{|c|} 
Sensor PZEM-004T \\
mendeteksi daya dari \\
beban yang terhubung \\
dengan sumber tegangan \\
\end{tabular}} & $\rightarrow \begin{array}{c}\text { Raspberry Pi 4B } \\
\text { menampilkan pembacaan } \\
\text { daya dari sensor }\end{array}$ & $\begin{array}{c}\text { Mengirimkan data daya } \\
\text { ke node } 1 \text { dengan } \\
\text { menggunakan } \\
\text { komunikasi MQTT } \\
\end{array}$ \\
\hline & & $\downarrow$ \\
\hline & \begin{tabular}{|c|} 
Informasi blok yaitu \\
blockhash dan data daya \\
akan ditampilkan pada \\
web pengguna \\
\end{tabular} & $\begin{array}{c}\text { Data daya disimpan ke } \\
\text { block lalu ditambahkan } \\
\text { ke blockchain }\end{array}$ \\
\hline
\end{tabular}

Gambar 6. Diagram Blok Proses Blockchain

Selanjutnya Gambar 7 menunjukkan diagram blok pengujian performa sistem smart energy meter. Pengujian performa dilakukan dengan pengecekan antara data yang dikirim dari Raspberry Pi ke node 1 dengan yang ditampilkan pada web pengguna, menghitung delay MQTT, delay pembuatan contract, delay submit transaction, delay proses transaksi, perbandingan delay konsensus antara dua node dan tiga node dan performa komputasi blockchain.

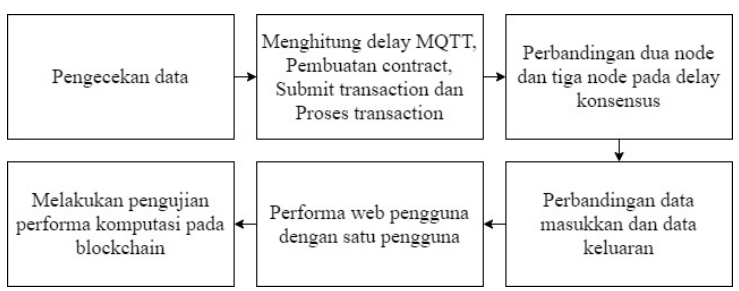

Gambar 7. Diagram Blok Pengujian Performa blockchain

\section{Desain Perangkat Smart Energy Meter}

Gambar 8 menunjukkan rancangan desain perangkat smart energy meter yang terdiri dari sensor PZEM-004T, Raspberry Pi 4B dan Monitor. Pada Raspberry Pi 4B sudah terintegrasi modul WiFi dan sudah terpasang sistem operasi raspberry debian agar dapat digunakan. Sehingga Raspberry Pi 4B dapat dihubungkan ke monitor yang nantinya penulis dapat membaca data dari sensor PZEM004T. Pembacaan data sensor tersebut diprogram menggunakan bahasa python yang sudah terintegrasi di raspberry debian.

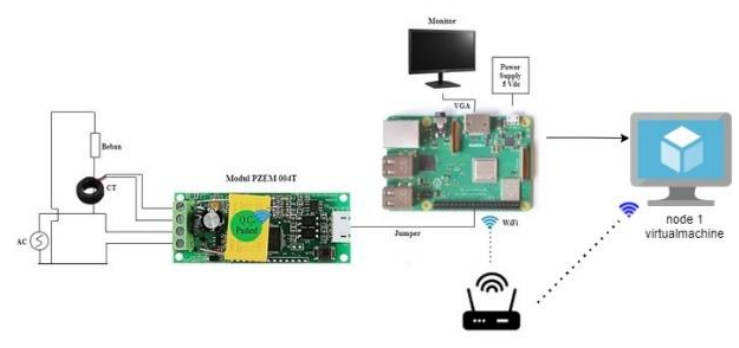

Gambar 8. Desain Perangkat Smart Energy Meter

\section{E. Desain Perangkat Lunak}

Gambar 9 menunjukkan diagram alir sistem blockchain yang dimulai dari proses mining node 1 dan node 2 agar nantinya dapat melakukan transaksi. Lalu data dikirimkan dari publisher Raspberry Pi ke subscriber node 1 ubuntu virtualbox menggunakan MQTT di mana alamat IP yang diatur sebagai broker yaitu 192.168.1.14 (merupakan IP address dari Raspberry Pi). Setelah node 1 menerima data selanjutnya proses penyimpanan dengan memanggil fungsi set menggunakan web3.py API yang mengakses fungsi-fungsi setData dari smart contract yang sudah dibuat lalu node 1 mengajukan transaksi (submit transaction) dan menghasilkan blok. Dalam proses penyimpanan blok ke blockchain terdapat 

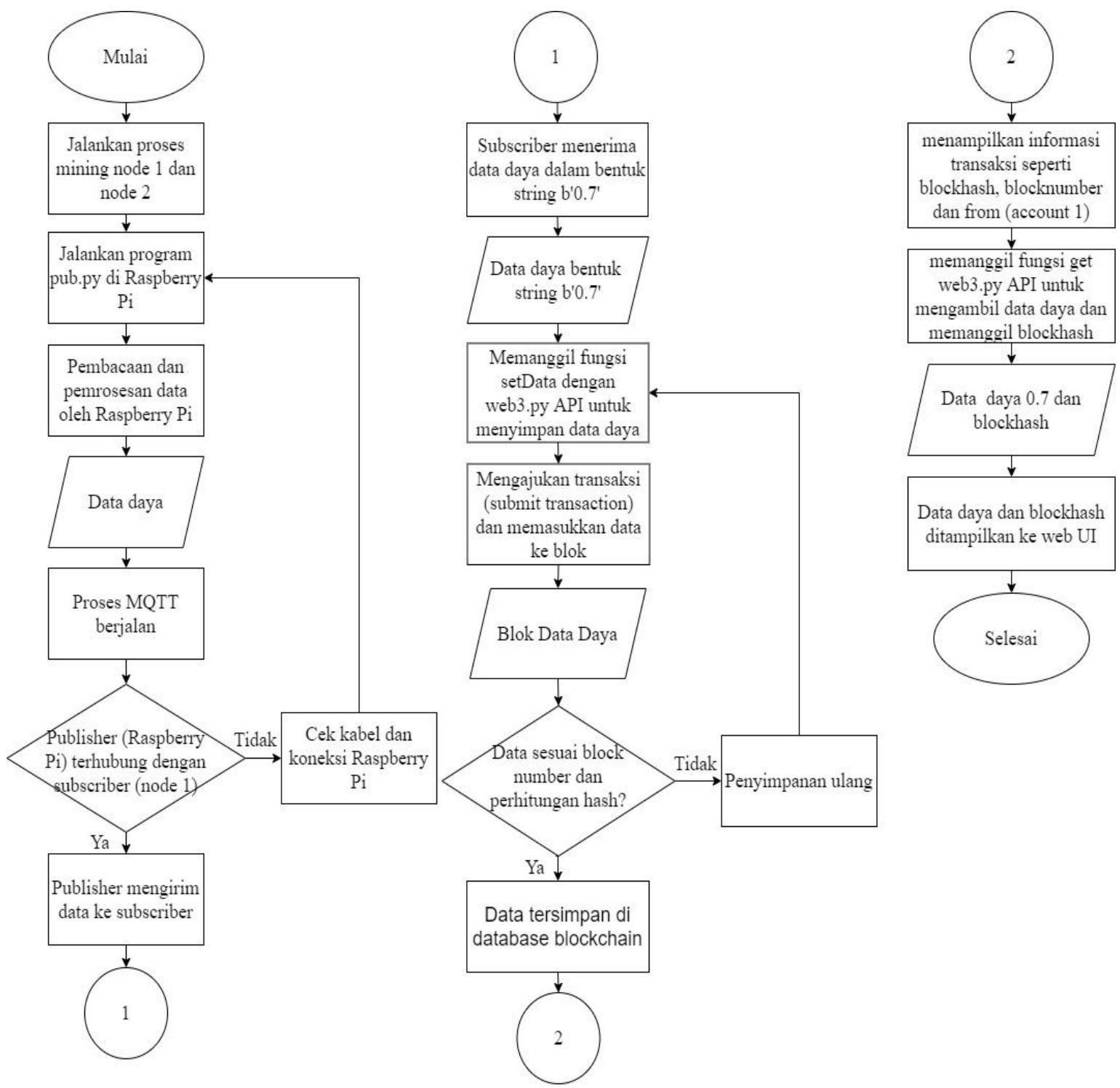

Gambar 9. Diagram Alir Sistem Blockchain

validator (account 1) yang memvalidasi penyimpanan tersebut, jika sesuai dengan block number dan hasil perhitungan hash selanjutnya maka berhasil disimpan dan account 1 menyetujui transaksi dan menyimpan blok ke blockchain. Setiap proses penyimpanan dilakukan transaksi antara account 1 dan account lainnya. Transaksi tersebut menghasilkan beberapa informasi yang penting dan sangat digunakan pada penelitian penulis adalah blockhash, blocknumber, from atau pengirim dalam transaksi tersebut dan hash transaksi. Setelah data berhasil disimpan pada database blockchain maka selanjutnya proses pengambilan data daya dan blockhash dengan memanggil fungsi getDaya menggunakan web3.py API untuk mengaksesnya. Untuk memanggil dan membaca data daya dan blockhash tersebut ke Web UI.

\section{HASIL DAN PEMBAHASAN}

Pada pengujian ini, langkah pertama menjalankan sistem yaitu dengan menjalankan program flask sekaligus web3. Lalu setelah flask sudah berjalan, maka mengakses URL web flask yaitu http://127.0.0.1:5000/. Selanjutnya menjalankan program di sisi Raspberry Pi untuk menghubungkan Raspberry $\mathrm{Pi}$ dengan node 1 melalui protokol MQTT. Berikut skenario pengujiannya:

\section{A. Pengecekan Data}

Pengecekan data dilakukan antara data yang diterima dan disimpan dengan data yang ditampilkan pada web pengguna. Data tersebut adalah daya dan blockhash. Hasil dari pengecekan data yang diterima dan data yang ditampilkan sama, sehingga data berhasil disimpan dan ditampilkan pada web 
pengguna. Hasil tersebut dapat dilihat pada Gambar 10.

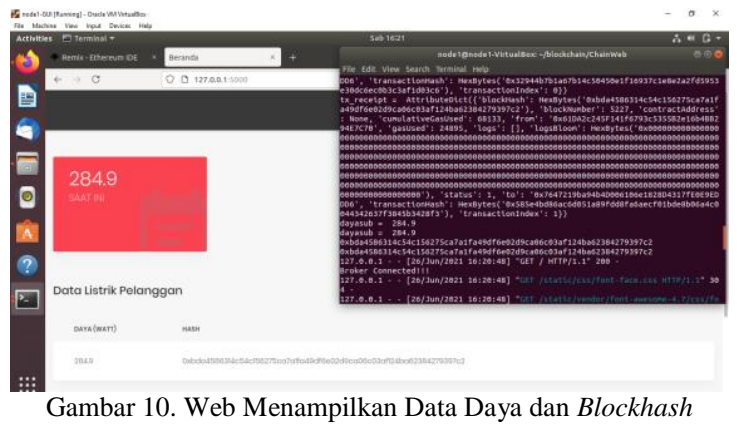

B. Pengukuran Delay Proses MQTT, Submit Transaction dan Transaction Resecipt

Pada bagian ini, penulis melakukan pengujian delay terhadap tiga proses sub-sistem seperti yang dijelaskan berikut ini.

1. Proses MQTT

Pengukuran delay MQTT menggunakan wireshark untuk mengambil waktu pemrosesan MQTT. Proses MQTT dapat dilihat pada wireshark yaitu dimulai saat node 1 dan Raspberry Pi terhubung, subscriber (node 1) melakukan request hingga publisher (Raspberry $\mathrm{Pi})$ mengirimkan data.

2. Proses Submit Transaction

Pengukuran delay submit transaction dilakukan pada saat data daya diterima hingga keluar submit transaction. Pengukuran tersebut dengan menggunakan library time dari python. Penulis menambahkan baris code start_time sebelum potongan program data daya diterima dan end_time setelah potongan program pemanggilan fungsi setData.

3. Proses Transaction Receipt

Pada proses transaction receipt, node validator melakukan validasi, jika berhasil maka membentuk tanda transaksi diterima. Pengukuran delay menampilkan data sama seperti pengukuran delay submit transaction yaitu dengan menggunakan library time dari python di mana menambahkan baris code start_time sebelum potongan program menampilkan tx_receipt dan end_time setelah potongan program untuk menampilkan transaction receipt.

Pengukuran delay pada protokol komunikasi MQTT didapatkan delay maksimal sebesar 30,07 detik. Hasil tersebut lebih besar 0,07 daripada interval waktu yang ditentukan oleh penulis pada source code python untuk publish data yaitu 30 detik. Namun hal tersebut tidak mempengaruhi hasil penerimaan data karena data sukses ditampilkan pada web pengguna. Hasil dari pengukuran delay pada proses submit transaction menunjukkan nilai maksimal yaitu 4,369 detik. Hasil pengukuran delay yang selanjutnya adalah pada proses transaction receipt. Hasil pengukuran tersebut menunjukkan nilai maksimal 7,431 detik. Jika dilakukan perhitungan total dari proses submit transaction hingga transaksi diterima yaitu 11,8 detik, sehingga pengaturan waktu interval pada program python MQTT di Raspberry Pi cukup baik yaitu mengirimkan setiap 30 detik, di mana data sukses dikirim dan disimpan. Namun jika dibandingkan dengan proses penyimpanan pada database tradisional yang bukan blockchain maka delay proses penyimpanan ke database blockchain lebih besar[20] dan tidak bisa digunakan untuk data realtime, hanya dapat digunakan untuk penyimpanan data dengan waktu proses sekitar 30 detik. Hasil pengukuran delay MQTT, submit transaction (Submit Tx) dan transaksi yang diterima (Tx Receipt) dapa dilihat pada Gambar 11.

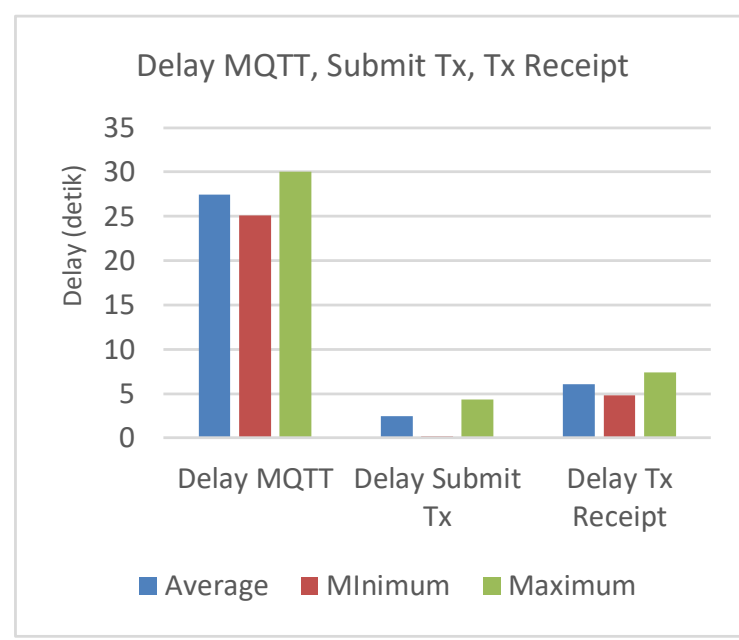

Gambar 11. Nilai Minimal, Rata-rata dan Maksimal dari Pengukuran Delay

\section{Proses Konsensus pada Dua Node dan Tiga Node}

Pengukuran dilakukan dengan memberi baris program start_time sebelum baris program pemanggilan fungsi set dan end time sebelum baris program menampilkan tx_receipt. Pengukuran delay konsensus ada dua pengukuran yaitu pada dua dan tiga node.

Pada pengukuran yang pertama dua node memiliki rata-rata delay konsensus lebih tinggi yaitu 3,154 detik dan pada tiga node rata-rata delay yaitu 2,349 detik. Sedangkan pada pengukuran yang kedua, tiga node memiliki rata-rata delay yang lebih tinggi yaitu 6,916 detik dan dua node memiliki rata-rata delay 6,468 detik. Hasil tersebut menunjukkan bahwa jumlah node tidak berpengaruh pada waktu konsensus. Dikarenakan menurut dari beberapa 
referensi yaitu jumlah node tidak terlalu mempengaruhi kinerja konsensus untuk beberapa konsensus seperti PoW dan PoA[21]. Yang mempengaruhi proses validasi adalah nilai komputasi atau CPU dan kualitas jaringan pada masing-masing node[22]. Berikut hasil pengukuran pada dua node dan tiga node pada Gambar 12 .

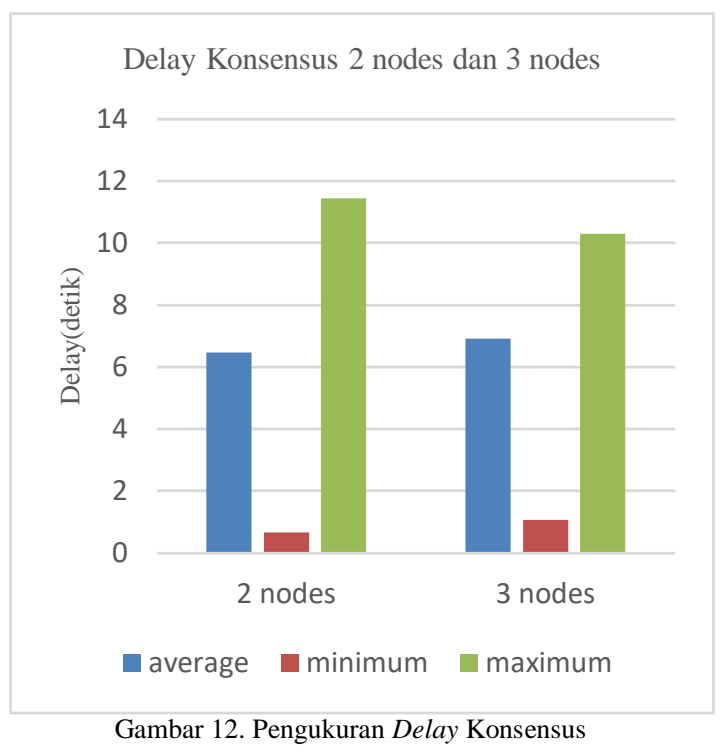

\section{Proses Pembuatan Smart Contract}

Pembuatan smart contract ini terjadi pada awal program dijalankan. Pengukuran delay pembuatan smart contract dilakukan dengan cara memantau pada geth console node 1, ketika memulai program web3 maka membuat smart contract. Pembuatan smart contract terjadi dua kali yang pertama dengan delay 0,001 detik dan yang kedua dengan delay 1,051 detik. Jika dijumlahkan total delay pembuatannya adalah sekitar 1 detik. Hasil tersebut tidak berpengaruh pada proses sistem karena pembuatan smart contract hanya pada awal proses saja.

\section{E. Perbandingan Panjang Blockchain Terhadap Delay Consensus}

Pengukuran dilakukan dengan memberi baris program start_time sebelum baris program pemanggilan fungsi set dan end time setelah baris program menampilkan blockhash. Ukuran blok pada blockchain didapat dari memanggil API web3 eth.getBlock('latest'). Pengukuran dilakukan pada ukuran data 36 byte dan ukruan blok yang tersimpan data yaitu 818 byte, sedangkan blok yang kosong 608 byte. Sekitar 17,5 jam di mana data akan dikirimkan setiap 15 detik. Total panjang blockchain yang dihasilkan selama pengukuran adalah $5,987 \mathrm{MB}$.

Pada hasil pengukuran delay konsensus dilakukan perhitungan rata-rata setiap $1 \mathrm{MB}$. Rata- rata delay konsensus yang dihasilkan pada ukuran panjang blockchain pada 1 MB sebesar 6,085 detik, pada ukuran panjang blockchain 2 MB sebesar 6,119 detik, pada ukuran panjang blockchain $3 \mathrm{MB}$ sebesar 6,105 detik, pada ukuran panjang blockchain $4 \mathrm{MB}$ sebesar 6,087 detik dan pada ukuran panjang blockchain 5 MB sebesar 6,11 detik. Berdasarkan hasil tersebut panjang blockchain tidak mempengaruhi delay konsensus karena grafik ratarata delay hampir memiliki besar delay yang sama yaitu sekitar 6 detik. Selain itu, mengapa panjang blockchain tidak mempengaruhi delay konsensus? karena proses validasi dilakukan pada blok yang akan disimpan dengan satu blok sebelumnya, Berikut hasil pengukuran dapat dilihat pada Gambar 13.

$$
\begin{array}{|l|l|l|}
\hline & \text { Delay Konsensus Terhadap Besar Blockchain } \\
\hline & & \\
\hline
\end{array}
$$

\section{F. Perbandingan Ukuran Data Input dan Blok Output}

Penulis menggunakan data random atau dummy untuk mendapat ukuran 500 byte, 400 byte dan 300 byte. Ukuran data masukkan didapat dari memasukkan library sys python untuk menggunakan sys.getsizeof() agar dapat menampilkan informasi ukuran data yang ingin ditampilkan. Informasi ukuran blok didapatkan dari API web3 yaitu eth.getBlock('latest') di mana akan menampilkan informasi blok yang terakhir melakukan transaksi. Berikut informasi masingmasing ukuran data kirim dan ukuran bloknya pada Tabel 1 .

TABEL I. INFORMASI UKURAN DATA KIRIM, DATA TERIMA DAN UKURAN BLOK

\begin{tabular}{|c|c|}
\hline Ukuran Data & Ukuran Blok \\
\hline 300 byte & 1461 byte \\
\hline 400 byte & 1685 byte \\
\hline 500 byte & 1910 byte \\
\hline
\end{tabular}

Penulis melakukan pengambilan data sebanyak 174 blok di mana 144 blok kosong dan 30 terisi data 
masukkan. Informasi masing-masing ukuran data dan ukuran blok dapat dilihat pada tabel 3.1 yaitu pada ukuran 500 byte memiliki ukuran blok 1910 byte maka untuk informasi blockhash, transaction hash dan informasi blok lainnya menghabiskan 1410 byte. Pada ukuran 400 byte memiliki ukuran blok 1685 byte maka untuk informasi blok lainnya menghabiskan 1285 byte. Dan pada ukuran 300 byte memiliki ukuran blok 1461 byte sehingga untuk informasi block selain data menghabiskan 1161 byte. Terdapat blok kosong yang tidak menyimpan data yaitu memiliki ukuran blok 608 byte.

\section{G. Pengukuran Komputasi Sistem Blockchain}

Menurut beberapa referensi jumlah node tidak terlalu mempengaruhi biaya komputasi proses konsensus pada skema PoW dan PoA[21]. Yang mempengaruhi proses validasi adalah nilai komputasi atau CPU dan kualitas jairngan pada masing-masing node[22]. Maka penulis melakukan pengujian performa komputasi pada blockchain dilakukan dengan membandingkan nilai proses CPU tanpa mining blockchain dengan proses pengiriman data dengan mining blockchain. Berdasarkan hasil performa dengan memantau monitor sistem komputasi pada ubuntu, maka hasilnya sistem operasi lebih berat dengan menjalankan mining blockhain karena mining tersebut digunakan juga untuk menyimpan data daya dari sistem IoT dan juga untuk mendapatkan data daya dan blockhash tersebut untuk ditampilkan pada web pengguna. Pemakaian CPU mencapai 100\% di mana itu nilai pemakaian tertinggi. Pemakaian memory mencapai lebih dari setengah kinerja memory yaitu $68,8 \%$. Untuk pemakaian partisi swap tidak digunakan karena nilai sama antara sistem operasi tanpa dan dengan sistem blockchain yaitu 9,7\%. Maka sistem blockchain harus menggunakan spesifikasi CPU, Harddisk dan Memory yang cukup tinggi. Gambar 16 merupakan grafik rata-rata nilai persentase CPU, memory dan partisis swap sebelum dan saat sistem blockchain berjalan.

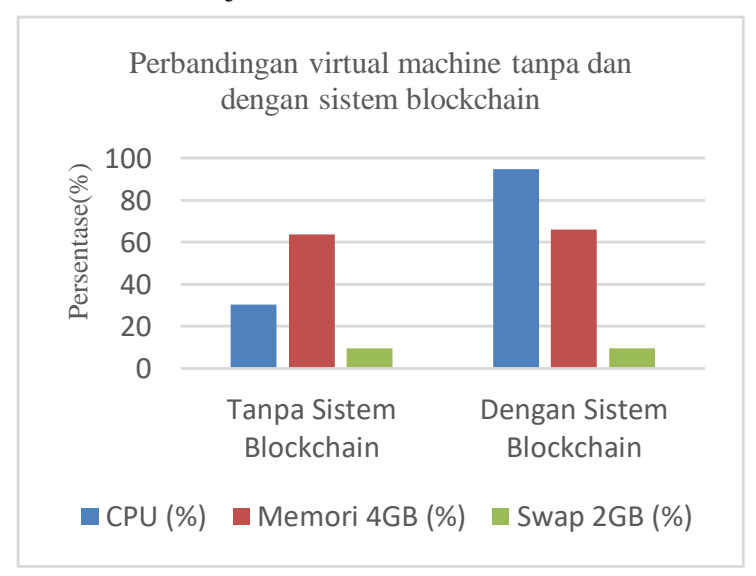

Gambar 16. Grafik Rata-rata Nilai CPU, Memory dan partisi Swap Sebelum Menjalankan Sistem Blockchain

\section{KESIMPULAN DAN SARAN}

\section{A. Kesimpulan}

Penelitian ini mengusulkan sistem blockchain sebagai database terdistribusi pada smart energy meter untuk meningkatkan kehandalan layanan database. Sistem blockchain ini diimplementasikan pada jaringan privat dengan menggunakan framework Ethereum. Hasil eksperimen menunjukkan bahwa komponen delay terbesar dalam sistem adalah pengiriman data dari Raspberry Pi ke node 1 yang menggunakan protokol MQTT. Pada eksperimen pembuatan blockchain, delay konsensus terpantau stabil terhadap ukuran blockchain. Namun, pada pengukuran performa komputasi, sumber daya komputasi jelas sangat terpengaruh dengan penggunaan blockchain yang mengakibatkan bebannya naik cukup signifikan mendekati kapasitas $100 \%$ dan $68,8 \%$ untuk CPU dan RAM pada node yang melakukan konsensus.

\section{B. Saran}

Agar lebih informatif untuk pengguna, maka sistem smart contract pada blockchain Ethereum perlu ditambah fitur untuk memodifikasi atau menambah parameter listrik lainnya. Server webhosting juga perlu ditambahkan ke dalam smart energy meter agar dapat diakses oleh banyak pengguna di internet.

\section{REFERENSI}

[1] M. Moniruzzaman, S. Khezr, A. Yassine, and R. Benlamri, "Blockchain for smart homes: Review of current trends and research challenges," Comput. Electr. Eng., vol. 83, p. 106585, 2020, doi: 10.1016/j.compeleceng.2020.106585.

[2] J. E. Siegel, S. Kumar, and S. E. Sarma, "The future internet of things: Secure, efficient, and model-based," IEEE Internet Things J., vol. 5, no. 4, pp. 2386-2398, 2018, doi: 10.1109/JIOT.2017.2755620.

[3] N. A. Prasetyo, A. G. Prabawati, and Suyoto, "Smart home: Power electric monitoring and control in Indonesia," Int. J. Interact. Mob. Technol., vol. 13, no. 3, pp. 143-151, 2019, doi: 10.3991/ijim.v13i03.10070.

[4] M. B. Mollah et al., "Blockchain for Future Smart Grid: A Comprehensive Survey," IEEE Internet Things J., vol. X, no. vi, pp. 1-1, 2020, doi: 10.1109/JIOT.2020.2993601.

[5] F. Dewanta and M. Mambo, "BPT Scheme: Establishing Trusted Vehicular Fog Computing Service for Rural Area Based on Blockchain Approach," vol. 70, no. 2, pp. 1752-1769, 2021, doi: 10.1109/TVT.2021.3051258.

[6] A. I. I. MuhammadRakha Laayu, Rendy Munadi, "Analisis Algoritma Advanced Encryption Standard (AES) Untuk Sistem Pemantauan Konsumsi Daya Listrik," e-Proceeding Eng., vol. 7, no. 3, pp. 88278833, 2020, [Online]. Available: https://openlibrarypublications.telkomuniversity.ac.id/i ndex.php/engineering/article/download/13956/13696.

[7] Y. Ren et al., "Multiple cloud storage mechanism based on blockchain in smart homes," Futur. Gener. Comput. Syst., vol. 115, pp. 304-313, 2021, doi: 10.1016/j.future.2020.09.019. 
G. S. Ramachandran et al., "Trinity: A Byzantine FaultTolerant Distributed Publish-Subscribe System with Immutable Blockchain-based Persistence," in 2019 IEEE International Conference on Blockchain and Cryptocurrency (ICBC), May 2019, pp. 227-235, doi: 10.1109/BLOC.2019.8751388.

[9] R. A. Atmoko, R. Riantini, and M. K. Hasin, "IoT real time data acquisition using MQTT protocol," J. Phys. Conf. Ser., vol. 853, no. 1, 2017, doi: 10.1088/17426596/853/1/012003.

[10] A. Dorri, S. S. Kanhere, R. Jurdak, and P. Gauravaram, "Blockchain for IoT security and privacy: The case study of a smart home," 2017 IEEE Int. Conf. Pervasive Comput. Commun. Work. PerCom Work. 2017, pp. 618-623, 2017, doi: 10.1109/PERCOMW.2017.7917634.

[11] L. Arief and T. A. Sundara, "Studi atas Pemanfaatan Blockchain bagi Internet of Things (IoT)," J. RESTI (Rekayasa Sist. dan Teknol. Informasi), vol. 1, no. 1, p. 70, 2017, doi: 10.29207/resti.v1i1.26.

[12] D. A. Badawi, "Sistem Verifikasi Dokumen Hasil Investigasi Digital Berbasis Teknologi Blockchain.” 2019.

[13] S. Ferretti and G. D'Angelo, “On the Ethereum blockchain structure: A complex networks theory perspective," Concurr. Comput. , vol. 32, no. 12, 2020, doi: $10.1002 /$ cpe. 5493 .

[14] P. Wackerow, "Intro to Ethereum," 2021. https://ethereum.org/en/developers/docs/intro-toethereum/.
[15] P. Sajana, "On Blockchain Applications : Hyperledger Fabric And Ethereum," vol. 118, no. 18, pp. 29652970, 2018.

[16] S. Al-Saqqa and S. Almajali, "Blockchain technology consensus algorithms and applications: A survey," Int. J. Interact. Mob. Technol., vol. 14, no. 15, pp. 142-156, 2020, doi: 10.3991/IJIM.V14I15.15893.

[17] J. C. Piper Merriam, "Introduction Web3.py," 2018 https://web3py.readthedocs.io/en/stable/.

[18] T. go-ethereum Authors, "Go Ethereum," 2021 https://geth.ethereum.org/.

[19] P. Wackerow, "Nodes and clients," 2021. https://ethereum.org/en/developers/docs/nodes-andclients/.

[20] M. J. M. Chowdhury, A. Colman, M. A. Kabir, J. Han, and P. Sarda, "Blockchain Versus Database: A Critical Analysis," Proc. - 17th IEEE Int. Conf. Trust. Secur. Priv. Comput. Commun. 12th IEEE Int. Conf. Big Dato Sci. Eng. Trust. 2018, no. August, pp. 1348-1353, 2018, doi: 10.1109/TrustCom/BigDataSE.2018.00186.

[21] Y. Wu, P. Song, and F. Wang, "Hybrid Consensus Algorithm Optimization: A Mathematical Method Based on POS and PBFT and Its Application in Blockchain," Math. Probl. Eng., vol. 2020, 2020, doi: 10.1155/2020/7270624.

[22] B. Cao et al., "Performance analysis and comparison of PoW, PoS and DAG based blockchains," Digit. Commun. Networks, vol. 6, no. 4, pp. 480-485, 2020, doi: 10.1016/j.dcan.2019.12.001. 